\title{
ON MULTIPLE FOURIER COEFFICIENTS OF FUNCTIONS OF $\phi-\Lambda$-BOUNDED VARIATION
}

\author{
R. G. VYAS AND K. N. DARJI
}

Abstract. Here, we have estimated the order of magnitude of multiple Fourier coefficients of functions of $\phi\left(\Lambda^{1}, \ldots, \Lambda^{N}\right) B V\left([0,2 \pi]^{N}\right)$.

Mathematics subject classification (2010): 42B05, 26B30, 26D15.

Keywords and phrases: Order of magnitude of multiple Fourier coefficients, functions of $\phi\left(\Lambda^{1}, \ldots, \Lambda^{N}\right) B V$.

\section{REFERENCES}

[1] A. N. BAKHVALOV, Fourier coefficients of functions from many-dimensional classes of bounded $\Lambda$ variation, Moscow Univ. Math. Bulletin, 66, 1 (2011), 8-16.

[2] V. FÜLÖP AND F. MóRICZ, Order of magnitude of multiple Fourier coefficients of functions of bounded variation, Acta Math. Hungar., 104, 1-2 (2004), 95-104.

[3] S. R. Ghorpade And B. V. Limaye, A Course in Multivariable Calculus and Analysis, Springer, 2010.

[4] F. Móricz And A. Veres, On the absolute convergence of multiple Fourier series, Acta Math. Hungar., 117, 3 (2007), 275-292.

[5] M. Schramm And D. Waterman, On the magnitude of Fourier coefficients, Proc. Amer. Math. Soc., 85, (1982), 407-410.

[6] R. G. VYAS, On the absolute convergence of small gaps Fourier series of functions of $\varphi \Lambda B V$, JIPAM. J. Inequal. Pure Appl. Math. 6 (2005), no. 4, Article 94, 5 pp.

[7] R. G. Vyas And K. N. DARJi, On multiple Walsh Fourier coefficients, J. Indian Math. Soc., 79, 1-4 (2012), 219-228. 